\title{
Sinking coastal cities
}

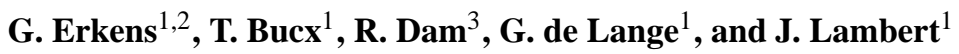 \\ ${ }^{1}$ Deltares Research Institute, Utrecht, the Netherlands \\ ${ }^{2}$ Utrecht University, Utrecht, the Netherlands \\ ${ }^{3}$ WaterLand Experts, Amsterdam, the Netherlands \\ Correspondence to: G. Erkens (gilles.erkens@deltares.nl)
}

Published: 12 November 2015

\begin{abstract}
In many coastal and delta cities land subsidence now exceeds absolute sea level rise up to a factor of ten. A major cause for severe land subsidence is excessive groundwater extraction related to rapid urbanization and population growth. Without action, parts of Jakarta, Ho Chi Minh City, Bangkok and numerous other coastal cities will sink below sea level. Land subsidence increases flood vulnerability (frequency, inundation depth and duration of floods), with floods causing major economic damage and loss of lives. In addition, differential land movement causes significant economic losses in the form of structural damage and high maintenance costs for (infra)structure. The total damage worldwide is estimated at billions of dollars annually.

As subsidence is often spatially variable and can be caused by multiple processes, an assessment of subsidence in delta cities needs to answer questions such as: what are the main causes? What is the current subsidence rate and what are future scenarios (and interaction with other major environmental issues)? Where are the vulnerable areas? What are the impacts and risks? How can adverse impacts be mitigated or compensated for? Who is involved and responsible to act?

In this study a quick-assessment of subsidence is performed on the following mega-cities: Jakarta, Ho Chi Minh City, Dhaka, New Orleans and Bangkok. Results of these case studies will be presented and compared, and a (generic) approach how to deal with subsidence in current and future subsidence-prone areas is provided.
\end{abstract}

\section{Introduction}

Currently, global mean absolute sea- level rise is around $3 \mathrm{~mm} \mathrm{yr}^{-1}$, and projections until 2100 based on Intergovernmental Panel on Climate Change (IPCC) scenarios expect a global mean absolute sea-level rise in the range of 3$10 \mathrm{~mm} \mathrm{yr}^{-1}$ (Church and White, 2011; Slangen, 2012). However, currently observed subsidence rates in coastal megacities are in the range of $6-100 \mathrm{~mm} \mathrm{yr}^{-1}$, and projections until 2025 expect similar subsidence rates (Fig. 1).

In coastal cities around the world, land subsidence increases flood vulnerability (flood frequency, inundation depth, and duration of floods), and hence contributes to major economic damage and loss of lives. Land subsidence is additionally responsible for significant economic losses in the form of structural damage and high maintenance costs; it affects roads and transportation networks, hydraulic infrastructure, river embankments, sluice gates, flood barriers, pump- ing stations, sewage systems, buildings, and foundations. The total damage associated with subsidence worldwide is estimated at billions of dollars annually.

There are no indications that neither subsidence nor the resulting damage will reduce in the near future. In fact, both are likely to increase. Ongoing urbanization and population growth in delta areas, in particular in coastal mega-cities, continues to fuel economic development in subsidence-prone areas. Consequently, economic development drives both the growing demand for groundwater, thereby increasing subsidence rates, and the growth of the total value of assets at risk. These impacts are aggravated on the long term in coastal areas, by expected future climate change impacts, such as sealevel rise, increased storm surges, and changes in precipitation.

In this paper, we focus on land subsidence in the urban environment, rather than land subsidence in rural agricultural areas, where the drivers may be similar, but the impact very 


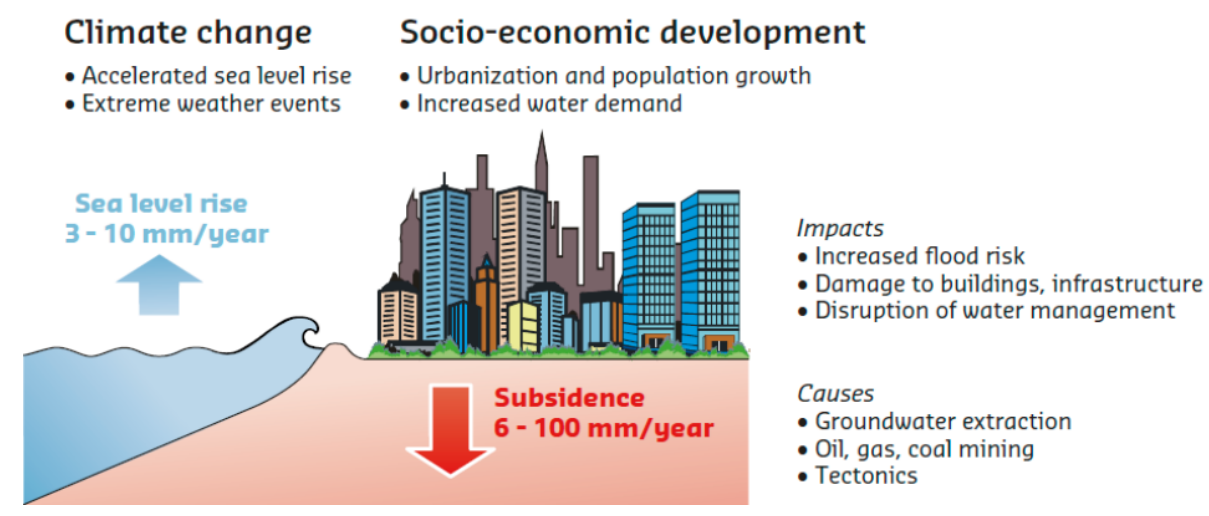

Figure 1. Drivers, processes and impacts of land subsidence in coastal cities. Land subsidence can exceed global absolute sea-level rise (SLR) with a factor 10 .

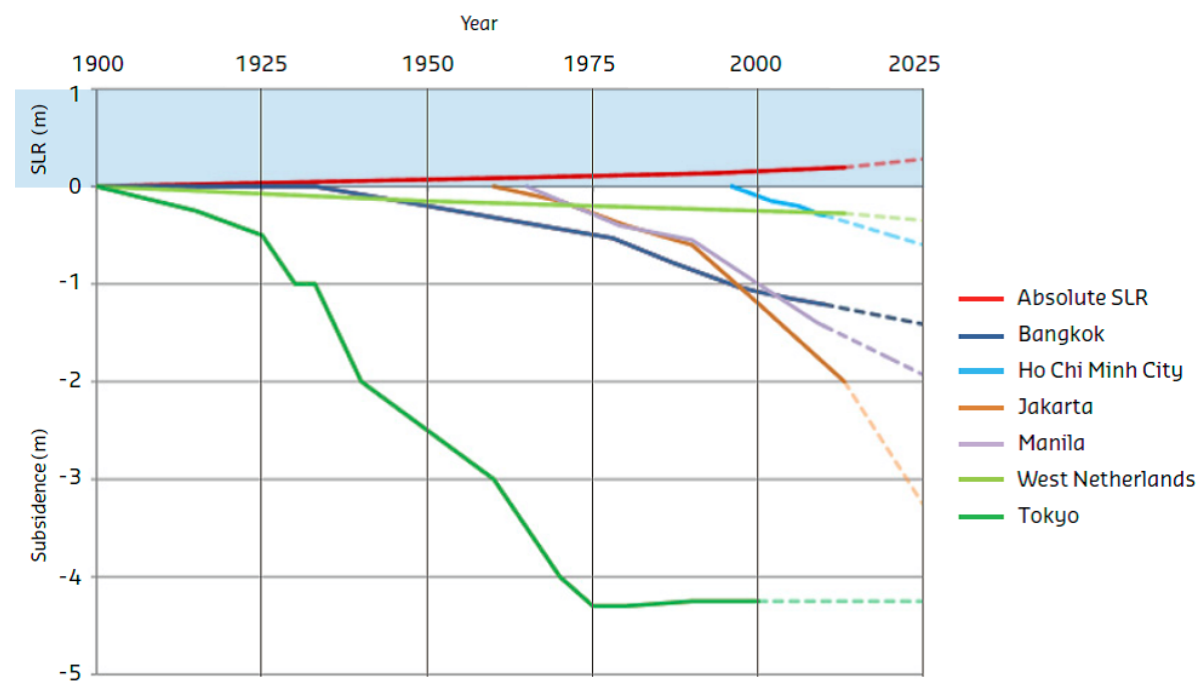

Figure 2. Subsidence history (cumulative) in a series of coastal cities around the world. Absolute sea level rise is depicted as reference. Subsidence can differ considerably within a city area, depending on groundwater levels and subsurface characteristics. Values provided here can be seen as average for the local subsidence hotspots. Some cities are currently seeing an acceleration of subsidence as a result of economic growth. Tokyo stands out as an example where subsidence has stopped after successful mitigation measures were implemented. The caption of Table 1 provides references.

Table 1. Subsidence in coastal cities. Estimated additional mean cumulative subsidence until 2025 (mm) are linear interpolations of the current rates, notwithstanding any policy changes. Sources: Bangkok: MoNRE-DGR (2012), Aobpaet et al. (2013); Ho Chi Min City: van Trung and Minh Dinh (2009); Jakarta: Bakr (2011); Manila: Eco et al. (2011); West Netherlands: van de Ven (1993); Tokyo: Kaneko and Toyota (2011).

\begin{tabular}{lrrrr}
\hline City & $\begin{array}{r}\text { Mean cumulative } \\
\text { subsidence in period } \\
1900-2013(\mathrm{~mm})\end{array}$ & $\begin{array}{r}\text { Mean current } \\
\text { subsidencerate } \\
\left(\mathrm{mm} \mathrm{yr}^{-1}\right)\end{array}$ & $\begin{array}{r}\text { Maximum } \\
\text { subsidence rate } \\
\left(\mathrm{mm} \mathrm{yr}^{-1}\right)\end{array}$ & $\begin{array}{r}\text { Estimated additional mean } \\
\text { cumulative subsidence } \\
\text { until 2025 (mm) }\end{array}$ \\
\hline Jakarta & 2000 & $75-100$ & 179 & 1800 \\
Ho Chi Minh City & 300 & up to 80 & 80 & 200 \\
Bangkok & 1250 & $20-30$ & 120 & 190 \\
New Orleans & 1130 & 6 & 26 & $>200$ \\
Tokyo & 4250 & $\approx 0$ & 239 & 0 \\
\hline
\end{tabular}


different. Figure 2 and Table 1 show that land subsidence rates widely vary from city to city. In many cases, the underlying processes and the relative contribution of the different drivers is not well understood. Similar to the level of technical understanding, policy formulation and governmental engagement in cities is equally diverse. Whereas some cities are in an early state of research and policy development on land subsidence, others have already implemented measures mitigating subsidence and the resulting damage. The observed different stages in development mean that cities can learn from each other, thereby avoiding re-inventing the wheel. Cities that actively pursue a policy on subsidence have valuable experiences to share with cities that have just started to address their subsidence.

This is exactly the thought behind the assessment that was carried out for this research. We compared five cities regarding their state of subsidence research and policy development: Jakarta, Ho Chi Minh City, Dhaka, New Orleans and Bangkok. The assessment aimed at getting insight into the processes causing subsidence in the urban environment, obtaining a (generic) research agenda for this topic, and listing best practice cases. Results of these case studies will be presented and a (generic) approach how to cope with subsidence in current and future subsidence-prone areas is provided.

\section{Results of the review}

For the quick assessment we used published reports on both the technical and the policy aspects of subsidence in the focus cities. In addition, we interviewed local scientist and policymakers to obtain their perspective. It became quickly clear that all cities tried to answer similar questions. We compiled the interview results into seven interrelated questions (Fig. 3). They include questions such as: what are the main causes for subsidence? How much is the current subsidence rate and what are future scenarios? Where are the vulnerable areas? What are the impacts and risks? How can adverse impacts be mitigated or compensated for? Who is involved and responsible to act? How to monitor the effect of the implemented measures? The interrelation between the questions is indicated with the arrows in Fig. 3. The indicated interrelation does not necessarily mean that each question needs to be answered in a specific order, but it merely indicates that each answer may be valuable input for a next question.

In this paper we follow this framework (in seven steps) and illustrate how these questions are addressed in example cities, thereby discussing both technical and policy aspects of subsidence. In this way, this framework could serve as a blue print for cities to shape their policy and research agenda regarding subsidence.

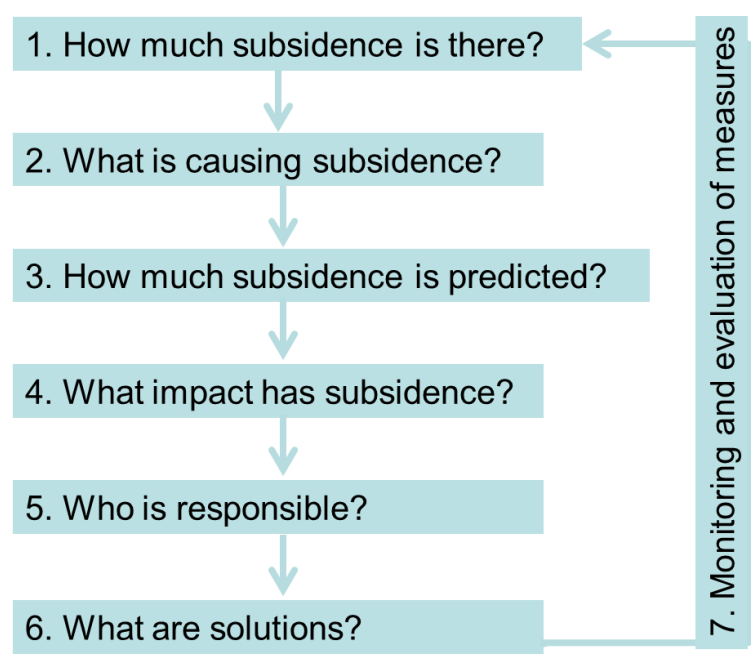

Figure 3. Seven questions that need to be addressed to pursue a successful policy to coop with subsidence. This is loosely based on the policy cycle, a popular framework to analyse policy development.

\section{Measuring and monitoring}

The first step towards a successful strategy for subsidence is to establish if a certain area is actually subsiding. This may not me evident from the field, particular if subsidence is nondifferential and no structural damage (cracks, tilting) is observed in buildings or infrastructure. Typically, the loss of elevation, which may have been observed, is interpreted as the result of climate-driven sea level rise instead of the result of subsidence.

To determine land subsidence rates, accurate measuring techniques are required. Continuous subsidence monitoring provides the necessary insight into changes - ranging from minor to very significant changes - in the topography of the urban area. These observations are also essential to validate subsidence prediction models in a later stage.

The following geodetric observation methods are being used:

- optical levelling;

- Global Positioning System (GPS) surveys;

- Laser Imaging Detection and Ranging (LIDAR);

- Interferometric synthetic aperture radar (InSAR) satellite imagery.

Following early work with systematic optical levelling nowadays GPS surveys and remote sensing techniques (LIDAR and InSAR) are deployed with impressive results. In contrast to surveys, LIDAR and InSAR images give a spatially resolved subsidence signal. InSAR images date back to the 1990s and can now be used to establish subsidence since that time. Application of this technique in soft soil areas is 
for the moment limited to the build-up environment, as a result of the need for stable reflectors. Ideally, multiple observation techniques are combined, for instance absolute measurements from GPS and Optical Levelling Spatially can be combined with remotely sensed, relative displacement measurements from InSAR. In this way, spatially resolved subsidence maps with respect to a global reference frame can be produced. InSAR measurement can therefore not replace periodic and systematic ground surveys, as they remain essential for ground truthing subsidence rates derived by remote sensing and as an independent source for validating subsidence prediction models.

Systematic observation of elevation forms the base for subsidence monitoring systems. Monitoring results can be used to develop a so-called dynamic digital elevation model (dDEM). This is not a static, one-time only (preferably high resolution) recording of the local topography, but an elevation model that can be corrected and updated from time to time, and that can be used in hydraulic models for flood prediction and urban water management.

All techniques mentioned above measure land surface elevation change, but give no information on the source of the subsidence. Subsidence benchmarks or extensometers can provide in-situ information of ground movement, as they record the volume reduction across a certain stretch in the subsurface, or even of individual geological layers. Ideally the benchmarks or extensometers need to be connected to surface movement observations, for instance by using a combined extensometer and continuous GPS station (e.g. Wang et al., 2014). Monitoring total subsidence at these "supersites", where a terrestrial network of site specific measurement stations is combined with remote sensing, forms the backbone of a spatially resolved subsidence measurement system (Allison et al., 2014). To support subsidence modelling, hydraulic heads of different aquifer systems and the phreatic groundwater level need to be monitored at these super sites as well. Measurements of geotechnical parameters at the same site provide additional necessary input for model studies.

\section{Unravelling the subsidence signal}

Subsidence can have natural as well as anthropogenic causes. The natural causes include tectonics, loading by ice sheets, by sediments, of by the ocean/sea (isostatic adjustment), and natural sediment compaction (autocompaction). Anthropogenic causes include compression of shallow soft layers by loading (with buildings for instance), or as a result of drainage and subsequent oxidation and consolidation of organic soils and peat. Alluvial or coastal sediments consisting of alternating layers of sand, clay, and peat are specifically compressible and vulnerable for oxidation. This is related to the physical characteristics of these sediments and makes low-lying coastal and delta areas specifically prone to subsi-

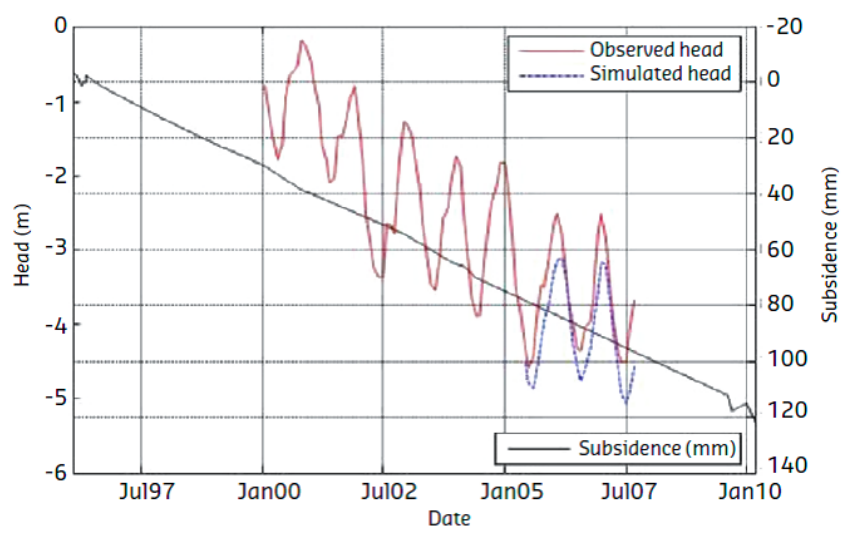

Figure 4. A distinct relation between falling hydraulic heads and subsidence in Ho Chi Minh City (Vietnam). This is indicative of an important contribution of groundwater over-exploration to subsidence, although it is not necessarily the only component contributing to the total subsidence signal.

dence. In deeper layers subsidence is caused by extraction of resources such as oil, gas, coal, salt, and groundwater.

In most of the large delta cities where land subsidence is severe (Jakarta, Ho Chi Minh City, Bangkok, Dhaka, Shanghai, and Tokyo), the main cause is extraction of groundwater. Rapidly expanding urban areas require enormous amounts of water for domestic and industrial water supply. This need often leads to over-exploitation of groundwater resources, especially when surface waters are seriously polluted (Jakarta, Dhaka). Dhaka (Bangladesh) is an example of a city that started to discover that it subsided after the flood frequency increased. In this rapidly expanding city data on subsidence and its impacts are currently largely lacking. Large-scale extractions cause groundwater levels to fall by $2-3 \mathrm{~m} \mathrm{yr}^{-1}$. At present, $87 \%$ of the supplied water is from groundwater extraction, and it has been acknowledged that a shift to using surface water instead is necessary. However, treating the polluted surface water is much more technically complex and expensive than extracting groundwater.

Although groundwater extraction is often not the sole source of subsidence, studies in many cities have revealed a distinct relation between falling groundwater levels and subsidence, indicative of an important contribution of aquifer compaction (Fig. 4). The resulting spatial pattern of subsidence and its progress over time are strongly related to the local composition of the subsurface and the number and positions of groundwater abstraction wells.

New Orleans (USA) is a prominent example of a city where an array of processes contributes to the total subsidence of the city. The Mississippi Delta subsides as a result of natural processes, such as autocompaction, faulting, sediment loading and isostacy (e.g. Törnqvist et al., 2008; Yu et al., 2012). Within the urban area of New Orleans, there additionally is anthropogenic induced subsidence as a result of drainage of shallow soft soils (Stuurman and Erkens, 2015) 


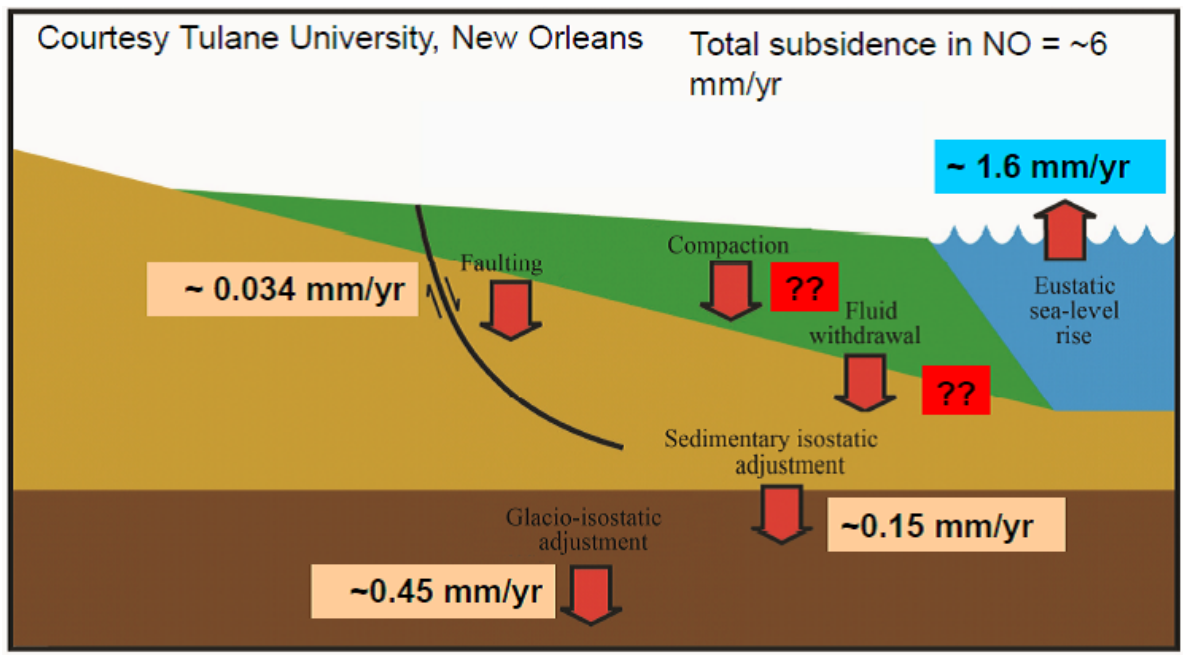

Figure 5. Subsidence components in the urban area of New Orleans. Values are derived from studies of Tulane University, New Orleans, and are indicative. The total subsidence rate is derived from InSAR measurements (Dixon et al., 2006). It shows that in the urban area natural subsidence forms the smaller portion of the total subsidence and that human induced subsidence dominates.

and extraction of deeper groundwater in confined aquifers, for industrial use mainly (Dokka, 2011). After drainage of the organic rich soils, they start to oxidize and lose volume, and this process will continue to cause subsidence as long as organic material is available in the drained subsoil.

The average measured subsidence rate in the city of New Orleans (including the urban area of Jefferson and St Bernard Parishes) is $6 \mathrm{~mm} \mathrm{yr}^{-1}$ (Dixon et al., 2006). Many studies try to quantify one or more of the different components contributing to the total measured subsidence. Figure 5 shows how this may look for New Orleans, when components are quantified step by step (source: Tulane University, New Orleans). In-situ observation data may provide an independent valuable source of information to unravel the total subsidence signal, as argued in Sect. 3. Another approach to unravel the subsidence signal is inverse modelling, whereby with the use of a careful inversion scheme, the available knowledge on the geology and hydrological dynamics of a system can be quantitatively constrained with subsidence observations (e.g. Fokker et al., 2007).

From Fig. 5 also follows that in the urban area of New Orleans, human induced subsidence has a much larger contribution to the total subsidence signal than natural subsidence. This is often the case, as natural subsidence rates are mainly limited to tens of millimeters per year, to millimeters per year in exceptional cases. Human induced subsidence rates can easily reach centimeters per year, to even tens of centimeters per year (e.g. Jakarta). For policy development this is an important notion: it is worthwhile to implement measures to reduce human-induced subsidence.

\section{Modelling subsidence to make predictions}

In step three, once the causes for land subsidence have been established (see Sect. 4), predictions can be made to get insight in future land subsidence. Land subsidence modelling and fore-casting tools are being progressively developed that enable quantitative assessment of medium- to long- term land subsidence rates, and determination of multiple causes. Modelling tools are ideally complemented with monitoring techniques (i.e., GPS leveling, the use of InSAR -monitoring techniques), see Sect. 3.

Because land subsidence is in many places closely linked to excessive groundwater extraction, we focus in this paper on modelling of aquifer compaction. One of the most widely used computer program to simulate vertical compaction in models of regional ground-water flow is MODFLOW SUBWT (Leake and Galloway, 2007). MODFLOW SUB-WT is developed by the US Geological Survey and uses changes in groundwater storage in subsurface layers (aquifers and aquitards) and accounts for temporal and spatial variability of geostatic and effective stresses to determine layer compaction.

In soft soils, such as unconsolidated Holocene layers of peat and clay, the classical consolidation theory by Terzaghi is unable to explain observed consolidation behaviour. These lithology form the aquitards and interbed units in confined aquifer complex systems, albeit often more consolidated, which start to compact after groundwater is extracted from the confined aquifers. Creep deformation is one of the typical processes that occur when the effective stress is increased in clay or peat soils. The creep deformation (also known as secondary strain) of soils is a secondary consolidation process that leads to a reduction in void ratio at con- 


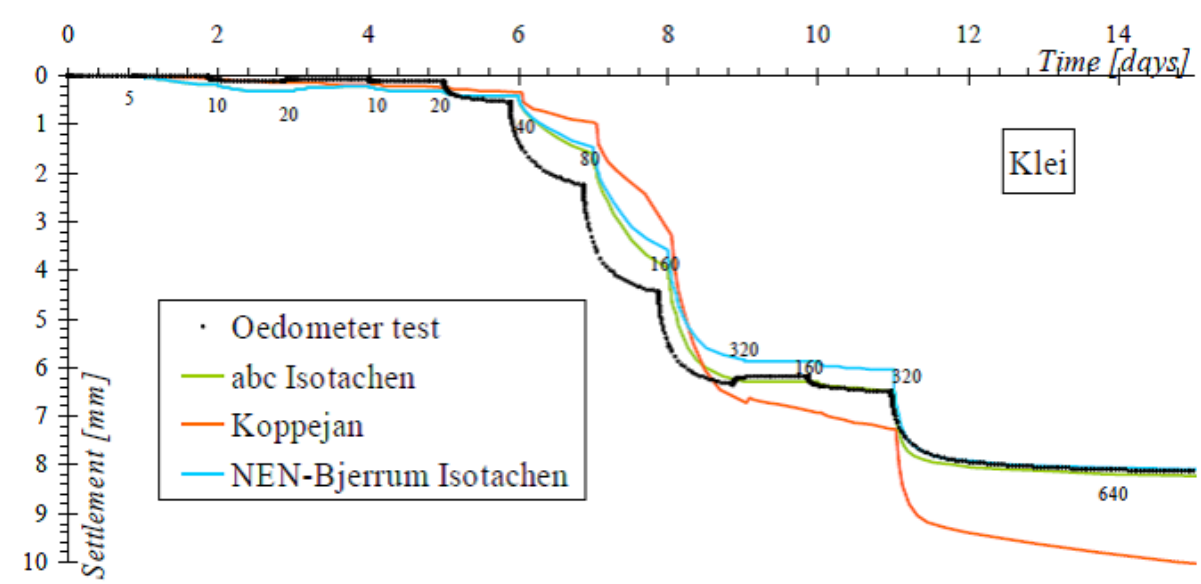

Figure 6. The performance of a series of models used to calculate settlement compared to Oedometer test results. Prediction made by classic models such as Koppejan fit the measurements less well compared to models based on the isotachs method, such as NEN-Bjerrum or abc-Isotachs.

stant effective stress, and consequently, to the development of an apparent pre-consolidation pressure (Den Haan, 1994). It is seen as visco-plastic behaviour and is considered a slow process, compared to primary or elastic consolidation. The inclusion of creep behaviour in numerical descriptions of the consolidation process has a long history, which is excellently described in Bakr (2015). An important aspect of the creep based models is that, due to secondary compression, there is a family of stress-strain curves rather than a single curve describing the relationship between stress and strain. Each of these curves, called "time lines" (i.e. isochrones), corresponds to a different duration of the applied load in a standard oedometer test. For soft soils, model predictions that make use of the isochrones method tend to match the oedometer test results best, specifically on longer time periods (Fig. 6).

Deltares Research Institute modified the US Geological Survey SUB-WT module by including isotachs (line of equal speed) based consolidation predictions. This model, MODFLOW SUB-CR (SUBsidence Creep), is used to determine medium- to long-term land subsidence trends under different scenarios of groundwater usage. In this way, the consequences of groundwater extraction for urban flood management become clear.

Because the SUB-CR model works with isotachs to calculate consolidation, it differs from the SUB-WT model in two ways:

- It predicts on the longer term more consolidation, thus subsidence, in clay and peat layers, as creep is a slow and largely irreversible component of subsidence

- Creep may continue for some time even after the hydraulic heads increased, introducing a time lag in consolidation.

As a result of these differences, aquifers with many finegrained interbeds, creep forms a considerable part of the to- tal amount of settlement over time and should not be neglected. An example is the subsidence predictions conducted for Jakarta, Indonesia, using isotachs-based consolidation calculations. Bakr (2015) calculates the subsidence occurring in four future groundwater management scenarios for Jakarta. The four scenarios are:

1. drawdown for all aquifers are kept zero till 2100 by maintaining piezometric levels at their values of 2010 (no change);

2. drawdown for all aquifers increase $5 \mathrm{~m}$ every 5 years from 2010 till 2030 (business as usual);

3. piezometric heads are recovered for all aquifers by 2015 to their values of 1995 (recovery),

4. piezometric heads are recovered for all aquifers by 2015 to the maximum level of all aquifers in 1995 (full recovery).

In Table 2, we report the predicted cumulative subsidence for Jakarta as calculated by Bakr (2015), calculated with the inclusion of creep. The results indicate that (i) if the hydraulic head declines continue with the current rate (scenario 2) parts of North Jakarta will sink an additional $3.9 \mathrm{~m}$, and (ii) even if hydraulic heads remain the same (scenario 1) or are restored (scenarios 3 and 4) subsidence continues, up to 2.3 or $2.4 \mathrm{~m}$ in the recovery scenarios in 2100 . This residual subsidence is the result of both delayed pore water pressure dissipation and visco-plastic creep compaction. This means that even if effective stresses do not change, land subsidence will continue till all layers reach hydrostatic equilibrium and creep compaction of all layers vanishes by time due to aging (Bakr, 2015).

This has important implications for policy development in the city of Jakarta. The significant predicted subsidence in the 
Table 2. Cumulative subsidence (m), modelled including creep behaviour, for 4 groundwater management scenarios for Jakarta, Indonesia, by Bakr (2015). Because of the slow creep rates, subsidence continues even after hydraulic heads are restored (scenarios 3 and 4 ).

\begin{tabular}{rrrrr}
\hline Year & $\begin{array}{r}\text { Scenario 1 } \\
\text { (no change) }\end{array}$ & $\begin{array}{r}\text { Scenario 2 } \\
\text { (business as usual) }\end{array}$ & $\begin{array}{r}\text { Scenario 3 } \\
\text { (recovery) }\end{array}$ & $\begin{array}{r}\text { Scenario 4 } \\
\text { (rapid recovery) }\end{array}$ \\
\hline 2020 & 1.97 & 2.48 & 1.74 & 1.73 \\
2025 & 2.08 & 2.75 & 1.80 & 1.77 \\
2030 & 2.18 & 2.92 & 1.85 & 1.81 \\
2100 & 3.01 & 3.91 & 2.43 & 2.30 \\
\hline
\end{tabular}

business as usual scenario justifies a subsidence mitigation policy. But the forecasted subsidence values in the recovery scenarios indicate that for the remaining residual subsidence an adaptation strategy must be developed too. Because of these far reaching implications for policy development, it is important that subsidence predictions are as accurate as possible. Although the inclusion of creep behaviour in prediction models aimed to increase accuracy of predictions, they are also sensitive for the geo(hydro)logical schematisation used in the model. This is because the fine-grained interbeds and aquitards are most sensitive to creep, and their exact distribution both in vertical and lateral direction determines the model outcome. The 3-D distribution of fine-grained deposits in the subsurface, and their geo-mechanical properties, are therefore key to reliable subsidence predictions for cities.

\section{Impact and damage}

With subsidence predictions for different management scenarios (step 3, see Sect. 5), damage estimates (step 4 in the framework, Fig. 3) provide additional information for policy decisions. The estimation of costs associated to subsidence is very complex. Subsidence is a "hidden threat" because in practice, costs appear on financial sheets as part of ad hoc investments or planned maintenance schemes, but are not labelled as subsidence-induced damage. Dedicated damage estimates of subsidence can help to raise awareness among policymakers and initiate policy development.

Generally, two (very different) types of damage as a result of subsidence can be recognised: (i) increased flood risk (due to increased flood frequency, floodwater depth, and duration of inundation) and more frequent rainfall-induced floods due to ineffective drainage systems, and (ii) damage to buildings, foundations, infrastructure (roads, bridges, dikes), and subsurface structures (drainage, sewerage, gas pipes, etc.). The former is mainly the result of non-differential subsidence, which is characteristic for large subsidence bowls that exist when groundwater or hydrocarbons at greater depth are extracted. Examples of cities that have increased flood risk as a result of subsidence include Jakarta, Ho-Chi-Minh and Bangkok. The second type of damage, to structures, is the result of differential subsidence. This commonly happens when fault systems are (re)activated, or when the subsidence is the result of shallow processes (loading or drainage of soft soils). Examples of cities in which structures are damaged include New Orleans, Venice (Italy) and Amsterdam (the Netherlands). Note that the construction site preparation and construction costs in soft-soil areas should be considered as subsidence-related costs, as these are mainly incurred to prevent consolidation. On the longer term, however, cumulative subsidence of soft soils may also increase flood risk as for instance happened in the Netherlands (subsidence over the last $\sim 1000$ years) or in New Orleans (subsidence over the last $\sim 150$ years). The extent of the damage is different in the two cases: increased flood risk usually applies to a larger area than structural damage that applies to single structures or parts of the network. The owner of the problem is also different: it is the local government who is investing in reducing flood risk, whereas local communities, (utility) companies or even home owners pay for the damage to (infra)structures.

Making an estimation of costs associated with subsidence is notoriously complex. Some bulk estimates are available. For instance, in China, the average total economic loss due to subsidence is estimated at around USD 1.5 billion per year, of which $80-90 \%$ is from indirect losses. In Shanghai, over the period 2001-2010, the total loss cumulates to approximately USD 2 billion. In the Netherlands, new estimates based on subsidence modelling, try to unravel the bulk costs. For instance, it is calculated that damage to foundations (as a result of subsidence) has been more than EUR 5 billion thus far, and might reach EUR 40 billion in 2050 (although this is a theoretical maximum, Hoogvliet et al., 2012). The communities in soft soil areas in the Netherlands spend EUR 0.25 billion per year more on maintenance than the communities on supportive soils. This values consists of EUR 0.17 billion per year maintenance for roads and water networks and EUR 0.08 billion per year for sewage systems (Lambert et al., 2014). The total damage associated with subsidence worldwide is unknown, but estimated based on the aforementioned values suggest billions of dollars annually. Because of ongoing economic and urban development, the potential damage costs of subsidence will increase considerably in the future, especially in subsidence-prone areas such as flood plains.

Damage estimates form the core of cost-benefit analyses. For subsidence, cost-benefit analyses will help to systematically calculate and compare benefits and costs of a decision 
or government policy on the short and long term. Being a gradual process, usually mitigation measures for subsidence are costly on the short term, but cost-effective on the longer term. Cost-benefit analyses could provide this insight in a quantitative way.

\section{Measures and monitoring}

Once the damage caused by subsidence is quantified (Sect. 6), the responsible actors (step 5 of the framework, Fig. 3) can work out a policy on subsidence (step 6), that should be evaluated after implementation (step 7). In this section we focus on action necessary for steps 6 and 7 .

There are generally two policy strategies for subsiding cities: mitigation and adaptation - analogue to the climate change policy discussions. A successful strategy, however, probably includes both. Mitigation only works for human-induced subsidence (Sect. 4). Typical mitigation measures include restrictions of groundwater extraction, artificial recharging aquifers, or raising (phreatic) water levels in areas with organic rich soils, thereby reducing oxidation of organic matter. Building with lighter materials decreases the load on soft soils, thereby decreasing consolidation and subsidence (Lambert et al., 2014).

For the human induced subsidence that cannot be mitigated, either because of technical difficulties (for instance the use of lighter building materials in high rise buildings), or because of financial reasons (i.e. the mitigation costs are too high), an adaptation strategy should be considered. This is also true for residual subsidence after a successful mitigation of subsidence (see Sect. 5) or for natural subsidence, where mitigation is not possible.

Adaptation must focus on reducing the impact of subsidence, for instance by decreasing the vulnerability of a certain asset to the negative impacts of subsidence. For increased flood risk as a result of subsidence, adaptation measures include the strengthening or heightening of embankments, building on mounds or piles, or conduct spatial planning in such a way that new constructions are only built on elevated areas. For damage to structures, adaptation strategies may include the use of flexible pipes and cables (specifically for connection points), the use of better foundations for structures, or again careful spatial planning, whereby building is limited to areas with supportive soils (for instance channel belt deposits within a delta).

Adaptation strategies are commonly applied in subsiding coastal cities, for instance most of them have network of embankments that reduces the flood risk. Cities that pursue an active policy on subsidence mitigation are less common, but successful examples do exist. In Tokyo, after taking regulations measures restricting the groundwater use were imposed in the early 1960s, the groundwater levels began to rise as a result (Fig. 7). Subsidence came to hold 10 years later as a result of the delayed response in the compacting layers (see

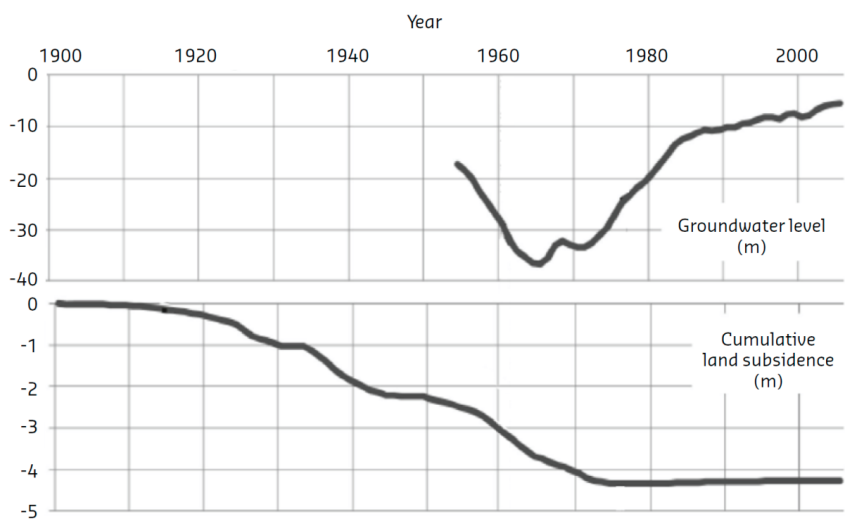

Figure 7. Land subsidence and groundwater levels in the Tokyo area (Japan), modified after Kaneko and Toyota (2011). The effect of the reduction of groundwater extraction on groundwater levels is clearly visible. Note that land subsidence completely stops 10 years after the groundwater level recovery started.

also Sect. 5). The restrictions on groundwater use meant that a replacement water source had to be found. Dams were constructed in several river basins that were designated for water resources development. During the 1970s and 80s numerous dams were built to provide storage to avoid future water scarcity and to supply the growing cities with sufficient water. Beginning in the 1960s an additional investment in waste water treatment was initiated.

Shanghai in China is another example of a city with a successful subsidence mitigation strategy. Following the increased understanding of the close relationship between groundwater extraction and land subsidence in Shanghai (e.g. Shi et al., 2008), groundwater levels were restored with active recharge techniques. Although this approach reduced the further lowering of groundwater tables and limited subsidence, it did not completely eliminate the effects of subsidence on infrastructure, roads, and buildings. The Shanghai case shows that, with active and substantial recharge, sustainable groundwater use is achievable, without severe subsidence, provided that average yearly pumping rates are in balance with the average yearly recharge.

In Bangkok, Thailand, regulation of and restrictions on groundwater extraction have successfully reduced severe land subsidence. A specific law (the Groundwater Act) was enacted in 1977. The most affected areas were designated as Critical Zones, and the government was given more control over private and public groundwater use in these areas. Groundwater use charges were first implemented in 1985 and have gradually increased. Currently about $10 \%$ of the total water use is supplied by groundwater extraction, and this mainly used by the industry in Bangkok. In most urban areas, subsidence is now reduced to $1 \mathrm{~cm} \mathrm{yr}^{-1}$, with local increased subsidence rates of $2 \mathrm{~cm} \mathrm{yr}^{-1}$ in the aforementioned industrial sites. 
Jakarta (Indonesia) and Ho-Chi-Minh City (Vietnam) are considering similar subsidence mitigation strategies. In the Greater Jakarta area, metropolitan authorities and technical agencies are advocating the reduction of groundwater extraction in vulnerable areas. The goal is to completely phase out the use of groundwater by taxing groundwater consumption. This would require developing an alternative water supply for large industrial users or relocation of large groundwater users, outside the so-called "critical zones". The number of "unregistered" users is still a problem. To some extent, spatial planning measures have been applied to avoid subsidence-prone areas, but the fast growth of informal settlements has made many of these plans obsolete. Recently, the Jakarta province government started to clear out the water management structures to reduce flood risk. In 2015, the Governor of Jakarta announced the reduction of the usage of deep groundwater in all government and public buildings, as a first step in the transition to piped water supply. The expected delayed response of subsidence to groundwater head recovery (Bakr, 2015; Sect. 5) asks for accurate subsidence prognosis. They form a vital component for any integrated flood management and coastal defence strategy (Dam, 2012).

Although land subsidence in Ho Chi Minh City has been observed since 1997, there is still - similar to Jakarta - considerable disagreement about the underlying processes and impacts. This is partly due to poor land level and groundwater extraction monitoring data (Ho Chi Minh City Flood and Inundation Management, 2013). Restrictions of groundwater extraction have been initiated, but it is too early to observe any effects.

In the Netherlands, with arguably the longest history of human induced subsidence in the world (since 1000 AD), the focus has been on adaptation strategies for more than nine centuries. In the coastal peatlands, after $\sim 1200 \mathrm{AD}$, adaptation measures included improving drainage (digging canals), the closing of (tidal) creeks and rivers, raising dikes and creating polders, and the improvement of foundations of buildings and infrastructure. Only in the last 50 years, with ever increasing damage to structures, mitigation measures were implemented. Nowadays, groundwater is sustained as shallow as possible in the peatlands. This means careful land use planning (less productive grassland and nature development in the most sensitive areas and considering alternative crops elsewhere) and the inlet of fresh water in polders in dry periods. Complete mitigation of subsidence is probably not possible, because that would end agriculture in a major part of western and northern Netherlands. The associated high economic losses are socially and culturally not acceptable. In the northern part of the Netherlands, gas extraction results in significant subsidence. Here policy similarly developed towards mitigation measures, albeit on a shorter time scale. Gas extraction started in the 1960's, but until about 2010 the governmental response to subsidence was limited to adaptation of the surface water management system. After 2010, subsidence was accompanied by more frequent and power- ful induced seismicity (earthquakes). The resulting damage of houses and other constructions forced the government in 2014 to start additional mitigation measures in the form of a significant reduction of gas exploitation in the most critical fields. Again, full mitigation was very difficult as stopping of the gas exploitation would endanger the national energy supply and would reduce the gas revenues by several billion of euro's per year. In addition, even if the gas exploitation was completely phased out, the subsidence and earthquakes are likely to continue. Concluding, for the Netherlands full mitigation of subsidence is far more expensive than implementing adaptation measures and an adaptation strategy combined with limited mitigation is a much more feasible option.

For all measures taken to reduce subsidence or its impacts, it is important that the effectiveness of these efforts is monitored. This implies that a subsidence monitoring network (see Sect. 3) need to be installed before the measures are implemented. The monitoring data form an important contribution to any subsidence monitoring network that has been established in step 1 (Sect. 3). Preferably, the monitoring data and analytical results (of the various modelling tools) are stored in a central database.

\section{Concluding remarks}

- In urban areas, human induced land subsidence dominates the total subsidence signal.

- Land surface elevation measurements need to be combined with in-situ measurements in order to be able to unravel the total subsidence signal.

- There are two types of damage as a result of subsidence: increased flood risk (with non-differential subsidence) and damage to structures (with differential subsidence).

- Analogue to climate change policies, a successful policy on subsidence consists of adaptation measures (reducing the damage and vulnerability) and mitigation measures (actively reducing subsidence).

- Delayed response of aquitards and interbed compaction may introduce unwanted additional subsidence after implementing mitigation measures, which is presently unaccounted for.

Acknowledgements. This study is based on research conducted by scholars working in the cities mentioned in this paper. They shared data and insights from which this study greatly benefitted. They are all gratefully acknowledged. 


\section{References}

Allison, M., Yuill, B., Törnqvist, T., Amelung, F., Dixon, T., Erkens, G., Stuurman, R. J., Milne, G., Steckler, M., Syvitski, J., and Teatini, P.: Coastal subsidence: global risks and research priorities, EOS Transactions, 2014.

Aobpaet, A., Caro Cuenca, M., Hooper, A., and Trisirisatayawong, I.: InSAR time series analysis of land subsidence in Bangkok, Thailand, Int. J. Remote Sens., 34, 8, 2013.

Bakr, M.: Land subsidence in North Jakarta - preliminary analysis results, part of Jakarta Coastal Defencse Strategy (JCDS) study, JCDS Atlas, 2011.

Bakr, M.: Influence of Groundwater Management on Land Subsidence in Deltas: A Case Study of Jakarta (Indonesia), Water Resour. Manage., 29, 1541-1555, doi:10.1007/s11269-014-0893-7, 2015.

Church, J. A. and White, N. J.: Sea-Level Rise from the Late 19th to the Early 21st Century, Surv. Geophys., 32, 585-602, 2011.

Dam, R.: Jakarta Coastal Defencse Strategy (JCDS) study, Activity Report: Land subsidence and adaptation/mitigation strategies, JCDS Bridging Phase, 2012.

Den Haan, E. J.: Vertical compression of soils, PhD thesis, Technical University of Delft, Delft, the Nehterlands, 1994.

Dixon, T. H., Amelung, F., Ferretti, A., Novali, F., Rocca, F., Dokka, R., Sella, G., and Kim, S.-W.: Subsidence and flooding in New Orleans - A subsidence map of the city offers insight into the failure of the levees during Hurricane Katrina, Nature, 441, 587$588,2006$.

Dokka, R. K.: New Orleans The role of deep processes in late 20th century subsidence of New Orleans and coastal areas of southern Louisiana and Mississippi, J. Geophys. Res., 116, 2011.

Eco, R. C., Lagmay, A. A., and Bato, M. P.: Investigating ground deformation and subsidence in northern Metro Manila, Philippines using Persistent Scatterer Interferometric Synthetic Aperture Radar (PSInSAR), American Geophysical Union, Fall Meeting, San Francisco, CA, USA, 5-9 December 2011, G23A-0822, 2011.

Fokker, P. A., Muntendam-Bos, A.-G., and Kroon, I. C.: Inverse modelling of surface subsidence to better understand the Earth's subsurface, First Break, 25, 8, 2007.

Ho Chi Minh City Flood and Inundation Management: Final Report, Volume 2: IFRM Strategy, Annex 3: Land Subsidence, Royal Haskoning-DHV and Deltares, 2013.

Hoogvliet, M., van de Ven, F., Buma, J., van Oostrom, N., Brolsma, R., Filatova, T., Verheijen, J., and Bosch, P.: Schades door watertekorten en - overschotten in stedelijk gebied - Quick scan van beschikbaarheid schadegetallen en mogelijkheden om schades te bepalen, Deltares report 1205463-000, 128 pp., 2012 (in Dutch).
Kaneko, S. and Toyota, T.: Long-Term Urbanization and Land Subsidence in Asian Megacities: An Indicators System Approach, in: Groundwater and Subsurface Environments: Human Impacts in Asian Coastal Cities, 2011.

Lambert, J. W. M., van Meerten, J. J., Woning, M. P., and Eijbersen, M. J.: Verbeterde onderhoud strategie infrastructuur in slappe bodemgebieden, Deltares report 1209950-000, 31 pp., 2014 (in Dutch).

Leake, S. A. and Galloway, D. L.: MODFLOW ground-water model, User guide to the Subsidence and Aquifer-System Compaction Package (SUB-WT) for water-table aquifers: US Geological Survey, Techniques and Methods 6-A23, 42 p., 2007.

MoNRE-DGR (Ministry of Natural Resources and Environment, Department of Groundwater Resources): The study of systematic land subsidence monitoring on critical groundwater used area project, Project report, 2012.

Shi, X., Wua, J., Yea, S., Zhangb, Y., Xuea, Y., Weic, Z., Lic, Q., and Yud., J.: Regional land subsidence simulation in Su-Xi-Chang area and Shanghai City, China, Engineering Geology, 100, $27-$ 42, 2008.

Slangen, A. B. A.: Towards regional projections of twenty-first century sea-level change based on IPCC SRES scenarios, Clim. Dynam., 38, 5-6, 2012.

Stuurman, R. J. and Erkens, G.: New Orleans' soft soils need water and solid management, J. Hydrogeol., in prepraration, 2015.

Törnqvist, T. E., Wallace, D. J., Storms, J. E. A., Wallinga, J., van Dam, R. L., Blaauw, M., Derksen, M. S., Klerks, C. J. W., Meijneken, C., and Snijders, E. M. A.: Mississippi Delta subsidence primarily caused by compaction of Holocene strata, Nat. Geosci., 1, 173-176, 2008.

van der Ven, G. P.: Man-made lowlands, history of water management and land reclamation in the Netherlands, Uitgeverij Matrijs, Utrecht, the Netherlands, 1993.

van Trung, L. and Minh Dinh, H. T.: Monitoring Land Deformation Using Permanent Scatterer INSAR Techniques (case study: Ho Chi Minh City), 7th FIG Regional Conference, Vietnam, 2009.

Wang, G., Yu, J., Kearns, T. J., and Ortega, J.: Assessing the Accuracy of Long-Term Subsidence Derived from Borehole Extensometer Data Using GPS Observations: Case Study in Houston, Texas, J. Surv. Eng., 140, 2014.

Yu, S.-Y., Törnqvist, T. E., and Hu, P.: Quantifying Holocene lithospheric subsidence rates underneath the Mississippi Delta, Earth Planet. Sci. Lett., 331-332, 21-30, 2012. 